\title{
The climatology of planetary boundary layer height in China derived from radiosonde and reanalysis data
}

\author{
Jianping Guo ${ }^{1, *}$, Yucong Miao ${ }^{1, *}$, Yong Zhang ${ }^{2}$, Huan Liu ${ }^{1}$, Zhanqing Li ${ }^{3,4}$, Wanchun Zhang ${ }^{1}$, Jing He$^{1}$, \\ Mengyun Lou ${ }^{1}$, Yan Yan ${ }^{1}$, Lingen Bian ${ }^{1}$, and Panmao Zhai ${ }^{1}$ \\ ${ }^{1}$ State Key Laboratory of Severe Weather \& Key Laboratory of Atmospheric Chemistry of CMA, \\ Chinese Academy of Meteorological Sciences, 100081 Beijing, China \\ ${ }^{2}$ Meteorological Observation Centre, China Meteorological Administration, 100081 Beijing, China \\ ${ }^{3}$ State Key Laboratory of Earth Surface Processes and Resource Ecology, College of Global Change and Earth System \\ Science, Beijing Normal University, 100875 Beijing, China \\ ${ }^{4}$ Dept. of Atmospheric \& Oceanic Sciences and ESSIC, University of Maryland, College Park, MD 20740, USA \\ *These authors contributed equally to this work.
}

Correspondence to: Jianping Guo (jpguocams@ gmail.com) and Zhanqing Li (zli@ atmos.umd.edu)

Received: 28 June 2016 - Published in Atmos. Chem. Phys. Discuss.: 11 July 2016

Revised: 14 October 2016 - Accepted: 18 October 2016 - Published: 28 October 2016

\begin{abstract}
The important roles of the planetary boundary layer (PBL) in climate, weather and air quality have long been recognized, but little is known about the PBL climatology in China. Using the fine-resolution sounding observations made across China and reanalysis data, we conducted a comprehensive investigation of the PBL in China from January 2011 to July 2015. The boundary layer height (BLH) is found to be generally higher in spring and summer than that in fall and winter. The comparison of seasonally averaged BLHs derived from observations and reanalysis, on average, shows good agreement, despite the pronounced inconsistence in some regions. The BLH, derived from soundings conducted three or four times daily in summer, tends to peak in the early afternoon, and the diurnal amplitude of BLH is higher in the northern and western subregions of China than other subregions. The meteorological influence on the annual cycle of BLH is investigated as well, showing that BLH at most sounding sites is negatively associated with the surface pressure and lower tropospheric stability, but positively associated with the near-surface wind speed and temperature. In addition, cloud tends to suppress the development of PBL, particularly in the early afternoon. This indicates that meteorology plays a significant role in the PBL processes. Overall, the key findings obtained from this study lay a solid foundation for us to gain a deep insight into the fundamentals of
\end{abstract}

PBL in China, which helps to understand the roles that the PBL plays in the air pollution, weather and climate of China.

\section{Introduction}

The planetary boundary layer (PBL), the lowest layer of the troposphere, is directly influenced by the Earth's surface, at a response timescale of about $1 \mathrm{~h}$ or less (Garratt, 1994; Stull, 1988). The accurate parameterization scheme with regard to how the PBL evolves is critical to the prediction of weather, climate and air quality, which heavily relies on the highresolution observations of atmospheric profiles (Hu et al., 2010; Wood, 2012; Xie et al., 2012). Through the PBL, the exchanges of momentum, water, heat and air pollutants take place between the Earth's surface and the free troposphere. To characterize the structure of PBL, the concept of boundary layer height (BLH) is commonly used (Seibert, 2000; Seidel et al., 2010), since the BLH determines the vertical extent of turbulent mixing, vertical diffusion and convective transport within PBL.

The development of PBL is dominated by complex surface forcings, including sensible heat flux, frictional drag, evaporation, transpiration and terrain-induced flow modification (Stull, 1988). As a result, the BLH is quite variable, both in time and space. During a diurnal cycle, the BLH is typically 
shallow (a few hundred meters) at night due to the strong near-surface stability, and the PBL can be well developed and reach several kilometers in the afternoon.

Traditionally, the BLH is diagnosed using the heightresolved observations of temperature, humidity and wind from radiosondes (Seibert, 2000; Seidel et al., 2010). The vertical resolution of these profiles is not sufficient to estimate BLH, since most soundings only provide a few records below $500 \mathrm{hPa}$ (Liu and Liang, 2010). Partly due to the lack of fine-resolution soundings, there have been rather limited investigations of the BLH climatology over specific locations and regions using atmospheric sounding data (Liu and Liang, 2010; Norton and Hoidale, 1976; Seidel et al., 2012).

In addition to the traditional radiosonde-based BLH algorithms, other methods relying on new data sources such as ground-based lidar (Hennemuth and Lammert, 2006; Sawyer and Li, 2013), sodar (Beyrich, 1997), ceilometer (Eresmaa et al., 2006), aircraft sounding (Dai et al., 2014) and spaceborne lidar (Chan and Wood, 2013; Liu et al., 2015; Zhang et al., 2016) instruments have been put forward to determine the PBL structure and its processes. However, the multiple types of observations tend to reveal different aspects of the PBL characteristics, due to the differing atmospheric variables used, leading to inevitable BLH differences (Seidel et al., 2012). Additionally, even for a single data source, the use of different methods to estimate BLH could yield a wide range of results (Seidel et al., 2010). If the same approach is applied to different types of measurements, such disagreements will be lowered (Sawyer and Li, 2013). Therefore, it is better to employ a consistent method to a single type of observation to construct the BLH climatology.

The BLH climatology has been highly sought in the PBL community, pioneered by the research of Holzworth (1964), who used early radiosonde data to study BLH over the United States, followed by the work of the US Environmental Protection Agency Air Quality Modeling Group, who makes the US mixing height data product publicly accessible (available at http://www.epa.gov/scram001/mixingheightdata.htm), but these data are only limited to the 1980s and thereafter. By extending the radiosonde data, new aspects of the BLH climatology over typical regions have been further investigated, producing a much clearer regional picture of BLH (Liu and Liang, 2010; Seidel et al., 2010; Sawyer and Li, 2013). A recent climatological BLH study (Seidel et al., 2012) gained new insight into the diurnal and seasonal variations of BLH over the continental United States and Europe by combining the radiosonde observations, a reanalysis and two climate models.

There were a host of studies (e.g., Zhang et al., 2014; Tang et al., 2016) that attempted to elucidate BLH characteristics in China, but most of them are limited to a specific place, let alone applicable to the BLH climatologies across China. They did not give much information of PBL over China, in part due to the lack of high-resolution observations in China prior to 2011. Since then, the radiosonde data have been ac- quired at a much higher vertical resolution ( $1 \mathrm{~s}$ resolution) across China by the China Meteorological Administration (CMA), presenting a unique opportunity to study the PBL features across China.

Using a consistent method and a traditional data source, radiosonde observations, BLH climatologies are presented in this study from the three and a half years of (from January 2011 to July 2015) sounding data acquired by the CMA sounding network, in conjunction with a modern reanalysis data product, to investigate the PBL climatology in China. To our knowledge, this is the first sounding-based nationwide PBL climatology in China. It provides us with a unique opportunity to explore the relationship between PBL structure and other meteorological parameters in China. This study of BLH climatology has important implications for better understanding the physical mechanisms, seasonal variation and spatial distribution of severe air pollution in China (H. Zhang et al., 2015; R. Zhang et al., 2015), since the PBL structure and processes play important roles in modulating the air quality (Guo et al., 2009, 2010; Hu et al., 2014; Miao et al., 2015; Lee et al., 2015). During the haze events the presence of aerosol can somehow modify the PBL meteorology and exacerbate pollution (Wang et al., 2013; Quan et al., 2013; Ding et al., 2016; Miao et al., 2016). For instance, the effects of black carbon particles on PBL have been adequately discussed in an earlier important publication (Zhang et al., 2008). Guo et al. (2014) found a lack of diurnal variation, but a cycle of 4-7 days in the aerosol properties, indicating a reduced PBL diurnal trend during polluted periods. Furthermore, another recent observation study (Peng et al., 2016) has demonstrated rapid aging of black carbon particles in China, leading to considerably enhanced light absorption, which suggests a large impact of atmospheric stabilization by black carbon particles. However, the main goals of this study are to investigate the BLH climatology in China, and to use it to explore its potential association with meteorology.

The remainder of this paper is organized as follows. Section 2 describes the data and method used, followed by the uncertainty analysis for the BLH retrievals in Sect. 3. Section 4 presents the climatology of BLH in China, as well as the associations with atmospheric variables. Finally, the key findings are summarized in Sect. 5.

\section{Data and methods}

The radiosonde network of the L-band sounding system dated back to 2002 when the China Meteorological Administration (CMA) began upgrading its radiosonde system. As of the beginning of 2011, deployment of the L-band sounding systems has been expanded to 120 operational radiosonde stations (Fig. 1). The GTS1 digital electronic radiosonde, one of the key components of the L-band sounding system, is now widely used in operational radiosonde stations in China, providing fine-resolution profiles of temperature, pressure, 


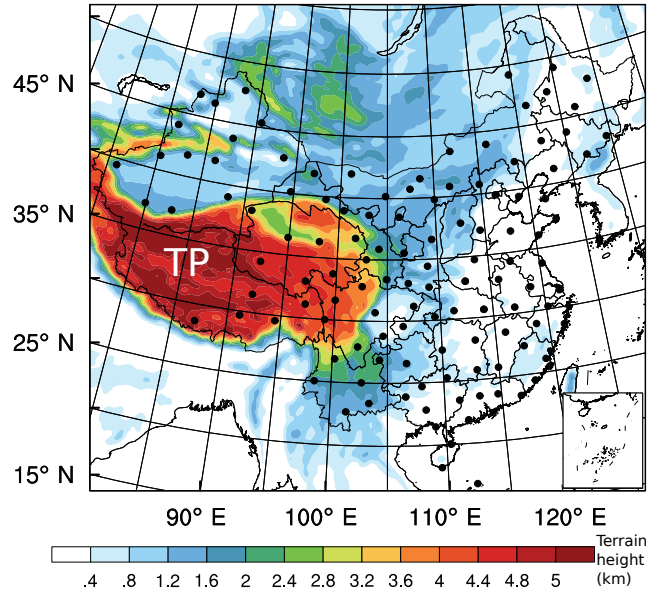

Figure 1. Spatial distribution of CMA sounding sites (black dots), overlaid over the terrain height (color shaded) of China. The white "TP" indicates the location of the Tibetan Plateau. This figure was plotted using the Lambert conformal conic projection.

relative humidity, wind speed and direction twice a day at 00:00 (08:00) and 12:00 UTC (20:00 BJT) (Fig. 2).

Previous intercomparison studies (e.g., Bian et al., 2011) indicate that the two types of radiosondes, i.e., Vaisala RS80 and GTS1, agree very well in the profile measurements in the troposphere (including PBL), albeit the large biases in the upper atmospheric levels. Therefore, the data from radiosondes of GTS1 are good enough to derive BLH for the superior performance in PBL.

The sounding data collected from 1 January 2011 to 31 July 2015 are used here to obtain the BLH at widely scattered radiosonde network across China. In total, we have made use of 391552 profiles across China, including 1578 profiles at 02:00 BJT, 190027 profiles at 08:00 BJT, 10313 profiles at 14:00 BJT and 189634 profiles at 20:00 BJT. In summer (the monsoon season), up to two additional soundings are launched occasionally at 06:00 UTC (14:00 BJT) and 18:00 UTC (02:00 BJT) during certain intensive observing periods at selected stations. The fine-resolution sounding observations provide essential information to investigate the diurnal structure of PBL.

In addition to the CMA sounding observations, the simultaneous profiling data of temperature and wind from ERAInterim reanalysis (Dee et al., 2011) are also used to derive BLH in this study. The ERA-Interim reanalysis assimilates a variety of measurements, including radiosonde observations at highly discrete levels (the so-called standard sounding levels), into weather prediction models in a physically consistent manner. The horizontal resolution of ERA-Interim reanalysis is $0.75^{\circ}$. In the vertical, there are 60 layers using hybrid coordinates that extend from the surface to the top of the $0.1 \mathrm{hPa}$ level, with 21 layers between the surface and $5 \mathrm{~km}$ above ground level (a.g.l.). The vertical resolution is about $20 \mathrm{~m}$ near the surface, and gradually decreases to about $200 \mathrm{~m}$ at $900 \mathrm{hPa}$ level and $500 \mathrm{~m}$ at $500 \mathrm{hPa}$ level.

Similar to the methods used by Seidel et al. (2012) to investigate the characteristics of BLH climatology in the United States and Europe, the bulk Richardson number $(R i)$ method (Vogelezang and Holtslag, 1996) was taken to simultaneously estimate the BLH from CMA soundings and ERAInterim data. The $R i$ method has been proven to be one of the best methods for BLH climatology analysis, since it is suitable for both stable and convective boundary layers, and can be applied to large amounts of radiosonde and reanalysis data (Seidel et al., 2012). Ri is defined as the ratio of turbulence associated with buoyancy to that induced by mechanical shear, which is expressed as

$\operatorname{Ri}(z)=\frac{\left(g / \theta_{\mathrm{v} s}\right)\left(\theta_{\mathrm{v} z}-\theta_{\mathrm{v} s}\right)\left(z-z_{s}\right)}{\left(u_{z}-u_{s}\right)^{2}+\left(v_{z}-u_{s}\right)^{2}+\left(b u_{*}^{2}\right)}$,

where $z$ denotes height above ground, $s$ the surface, $g$ the acceleration due to gravity, $\theta_{\mathrm{v}}$ virtual potential temperature, $u$ and $v$ the component of wind speed and $u_{*}$ the surface friction velocity. $u_{*}$ can be ignored here due to the much smaller magnitude compared with bulk wind shear term in the denominator (Vogelezang and Holtslag, 1996). Note that the $R i$ is dimensionless, and has nothing to do with the intensity of turbulence, but it can determine whether the turbulence exists or not. Previous theoretical and laboratory studies (e.g., Stull, 1988) suggested that when $R i$ is smaller than the critical value $(\sim 0.25)$, the laminar flow becomes unstable. Thus, the lowest-level $z$ at which interpolated $R i$ crosses the critical value of 0.25 is referred to as BLH in this study, similar to the criteria used by Seidel et al. (2012). A case in point for the BLH derived from sounding profiles in Beijing $\left(116.47^{\circ} \mathrm{E}, 39.80^{\circ} \mathrm{N} ; 32 \mathrm{~m}\right.$ a.s.1.) is presented in Fig. 2. For purposes of simplicity and clarity, the BLHs derived from CMA soundings and ERA-Interim reanalysis are referred to as CMA-BLH and ERA-BLH hereafter, respectively. Unless noted otherwise, all the values of BLH are presented with reference to the height above ground level, rather than that above sea level, to rule out the impact of topographic variation.

For the intercomparison between ERA-BLH and CMA$\mathrm{BLH}$, all profiles from reanalysis have been sampled at nine grid points centered at the radiosonde locations. Meanwhile, the ERA-Interim reanalysis data were sampled at 00:00 (08:00), 06:00 (14:00), 12:00 (20:00) and 18:00 UTC (02:00 BJT) to match the radiosonde observation times. Using instantaneous BLH estimates from the radiosondes and ERA-Interim, we computed seasonal-averaged (DJF, MAM, JJA, and SON) 5th, 25th, 50th, 75th and 95th percentile BLH values for each station or grid point investigated, separately for 02:00, 08:00, 14:00 and 20:00 BJT. 

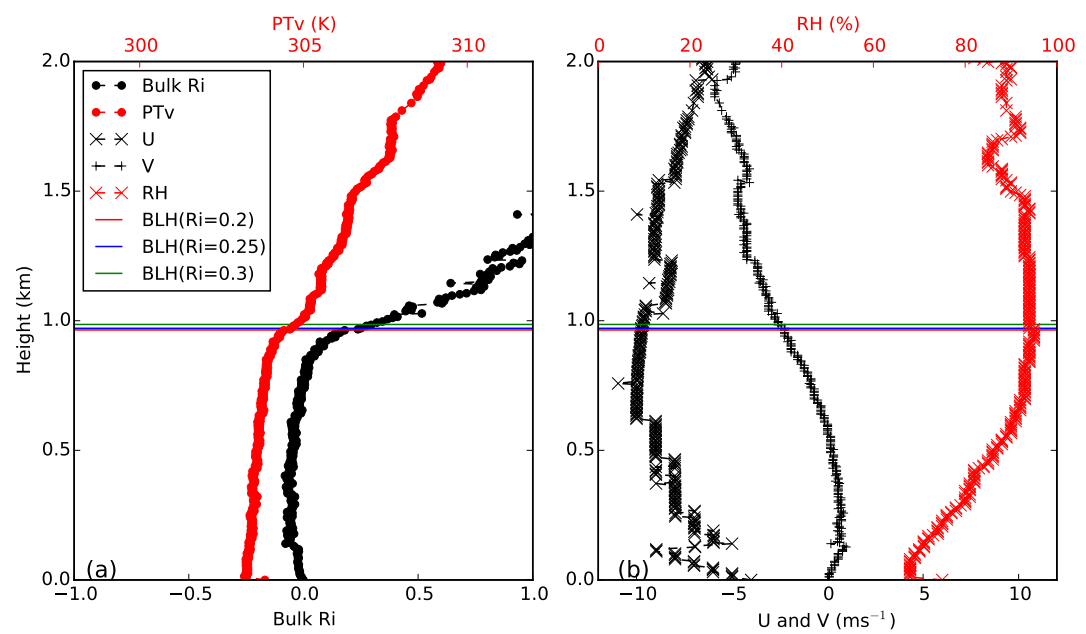

Figure 2. Vertical profile of (a) virtual potential temperature $\left(\mathrm{PT}_{\mathrm{V}}\right)$, bulk Richardson number $(R i)$, (b) wind speed $(U$ and $V)$ and relative humidity (RH) based on the 20:00 BJT 03 August 2012 radiosonde observation at the Beijing site. The horizontal lines indicate boundary layer heights (BLH) computed using 0.2 (red), 0.25 (blue) and 0.3 (green) as critical bulk Richardson number values.

\section{Uncertainty analysis}

Since the selection of critical $R i$ may bring uncertainty to the estimated BLH from the bulk Ri method as shown in Eq. (1), one case study has been carried out based on the 20:00 BJT 3 August 2012 radiosonde observation at the Beijing site. The BLHs for differing critical values of $0.2,0.25$ and 0.3 were then derived in an attempt to quantify the uncertainties. As illustrated in Fig. 2, the difference among the BLHs computed using different critical $R i$ can be hardly recognized, although the BLH of $R i=0.3$ seems slightly higher.

In the spirit of overall evaluation of the ensemble BLH estimations, scatter plots have been made to show CMABLHs computed using 0.2 and 0.25 as critical $R i$ values, vs. using 0.25 and 0.3 as critical $R i$ values. As expected, the CMA-BLHs of $R i=0.3(0.2)$ are generally higher (lower) than those of $R i=0.25$; however, the CMA-BLHs based on various $R i$ values are significantly correlated with each other $(R=0.99)$. Figure $3 \mathrm{c}-\mathrm{d}$ present the uncertainties as a function of BLHs $(R i=0.25)$. It is found that the 50th and 75th percentile values of the absolute uncertainties are $<0.05 \mathrm{~km}$ and $<0.1 \mathrm{~km}$, respectively; and the 50th and 75th percentile values of the associated relative uncertainties are both $<5 \%$ for BLH $(R i=0.25)>2 \mathrm{~km}$, and $<15 \%$ for BLH $(R i=0.25)<2 \mathrm{~km}$. As such, the uncertainty caused by the selection of critical value is quite small.

\section{Results and discussion}

This section presents the basic BLH climatologies from the CMA radiosondes and ERA-Interim, including seasonal and diurnal variations. Intercomparisons of climatological results from radiosonde observations with the ERA-Interim are made to better elucidate the BLH characteristics in China. Fi-
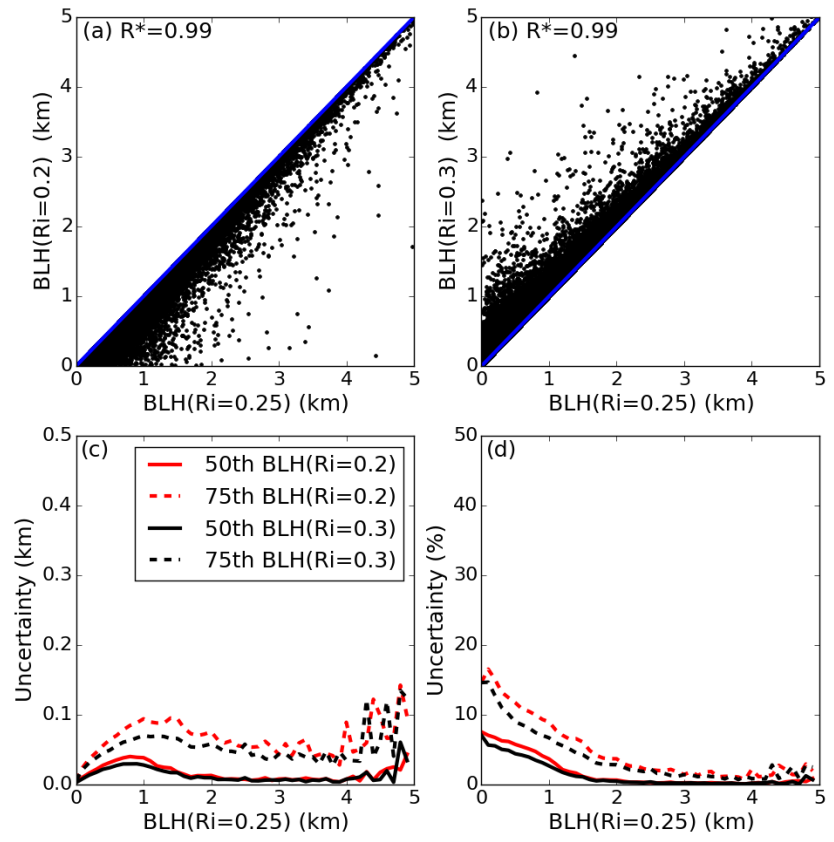

Figure 3. Scatter plots showing (a) CMA-BLHs computed using 0.2 and 0.25 as critical $R i$ values, and (b) CMA-BLHs computed using 0.25 and 0.3 as critical $R i$ values, both of which are based on 391552 soundings across China from January 2011 to July 2015. The 50th and 75th percentile values of (c) absolute uncertainty and (d) relative uncertainty using 0.2 and 0.3 as critical $R i$ values are shown as well. The correlation coefficients $(R)$ are given in the top panels, where the star superscripts indicate that values are statistically significant $(p<0.05)$. 

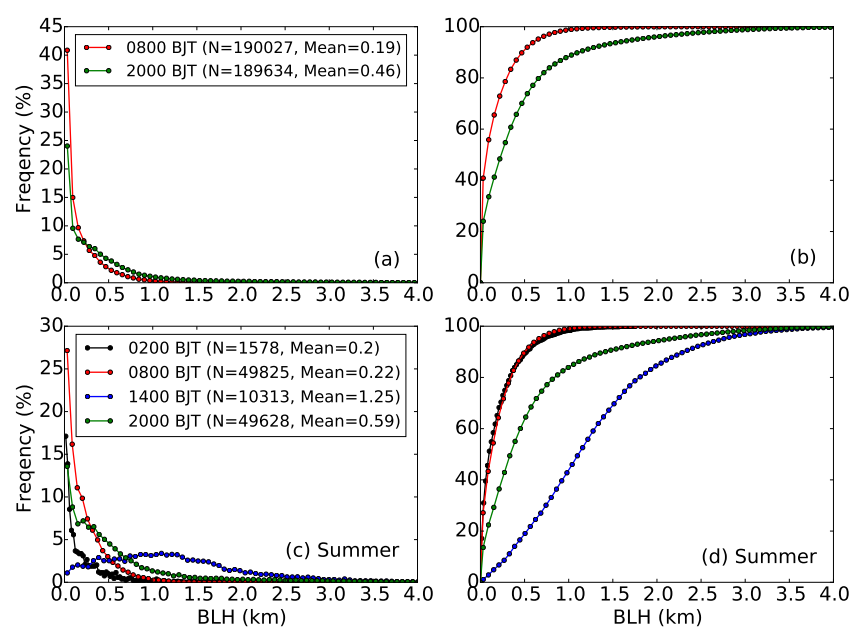

Figure 4. Frequency distribution (left) and cumulative frequency distribution (right) of CMA-BLH at 02:00 (in black), 08:00 (in red), 14:00 (in blue) and 20:00 BJT (in green) during (a, b) the whole period and (c, d) the summertime from January 2011 to July 2015. The number of soundings $(N)$ and mean value at each observed time are also given. Note that the soundings at 02:00 and 14:00 BJT are occasionally launched during certain intensive observation periods in summer.

nally we will explore the potential influences of meteorology on the observed annual cycle of BLH.

\subsection{Overall climatological pattern}

Figure $4 \mathrm{a}-\mathrm{b}$ present the frequency distributions of CMABLH at 08:00 and 20:00 BJT. At 08:00 BJT, almost all the CMA-BLHs are lower than $1 \mathrm{~km}$, with a mean value of merely $0.19 \mathrm{~km}$. The CMA-BLHs at 08:00 BJT are typically lower than those at 20:00 BJT.

The frequency distributions of summertime CMA-BLH at four observed times (02:00, 08:00, 14:00 and 20:00 BJT) are also illustrated in Fig. 4c-d. During a diurnal cycle, the CMA-BLH peaks in the afternoon (14:00 BJT), with a mean value of $1.25 \mathrm{~km}$. After sunset, the daytime convective boundary layer undergoes a transition into the nocturnal stable boundary layer. The soundings of 20:00 BJT provide information about the transition state, and the soundings of 02:00 BJT capture the nocturnal boundary layer. The next morning (around 08:00 BJT), after sunrise, the PBL experiences another transition to the convective boundary layer.

\subsection{Seasonal variation of CMA-BLH and ERA-BLH and their intercomparison}

Since only the soundings of 08:00 and 20:00 BJT are launched conventionally, the seasonal variation of BLH is mainly investigated at these two times (Fig. 5). At 20:00 BJT, the CMA-BLH generally follows a downward trend from spring to winter (Fig. 5b), that is, spring
$>$ summer $>$ fall $>$ winter. The climatologically strongest near-surface wind speed in most of China is in spring (Guo et al., 2011; Zhao et al., 2009), and the intense solar radiation is in summer (Miao et al., 2012, 2015), which favors the development of the boundary layer during these two seasons. In spring, the mean value of CMA-BLH is $\sim 0.71 \mathrm{~km}$, which is slightly higher than that of summer $(\sim 0.65 \mathrm{~km})$ but can occasionally exceed $2 \mathrm{~km}$ (95th percentile value) in spring and summer.

In contrast, in fall and winter, the mean values of CMABLH are merely $\sim 0.32 \mathrm{~km}$, which are significantly lower than those of spring and summer. Such a huge difference of the seasonally averaged CMA-BLH between the warm seasons (spring and summer) and cold seasons (fall and winter) at 20:00 BJT is well captured by the ERA-BLHs, although the ERA-BLHs tend to underestimate the springtime BLHs, and overestimate that of summer (Fig. 5b). The scatter plots of seasonally averaged CMA-BLHs and ERA-BLHs (Fig. 6) demonstrate the close correspondence between these two kinds of BLH, and give confidence that the seasonally averaged ERA-BLHs can be used as an alternative when the CMA soundings are unavailable. It is interesting to note that at 08:00 BJT the CMA-BLH of spring is not generally higher than that of summer, although the near-surface wind speed is stronger in spring for both 08:00 and 20:00 BJT (Figs. S1-S2 in the Supplement). This is most likely due to the stronger near-surface stability in spring (Fig. S3), which to some extent inhibits the development of PBL.

In terms of the spatial distributions of BLHs, a solar radiance difference is recorded at various stations or grid points across China due to the large spatial range. For a sounding observation at a given time (e.g., 02:00, 08:00, 14:00, 20:00 BJT), zonal evolution of BLHs has to be considered from the perspective of actual solar radiance recorded in the given area.

The spatial distributions of seasonally averaged CMABLHs and ERA-BLHs at 08:00 BJT are presented in Fig. 7. At 08:00 BJT, due to the stronger solar radiation in eastern China than that of western regions, higher BLHs can be distinctly seen over the eastern regions (Fig. 7). This BLH spatial pattern is more prominent in spring and summer than in fall and winter (Fig. 7a-b). Compared with the BLHs at 20:00 BJT, it is found that the BLHs of 08:00 BJT are generally lower (Figs. 4a and 5), and the seasonal variation of BLH is weaker. Despite these differences, the BLHs of 08:00 BJT show a similar seasonal variation; that is, there are higher BLHs in spring and summer. It is also intriguing to note that the highest ERA-BLH at 08:00 BJT over the northern Tibetan Plateau (TP) region occurs in winter (Fig. 7), which may be caused by the strongest near-surface wind over the northern TP region (Fig. S4). Since there is no available sounding observation in the northern TP region, the seasonal variation of ERA-BLH in this region cannot be characterized in this study, which necessitates further field campaigns. 

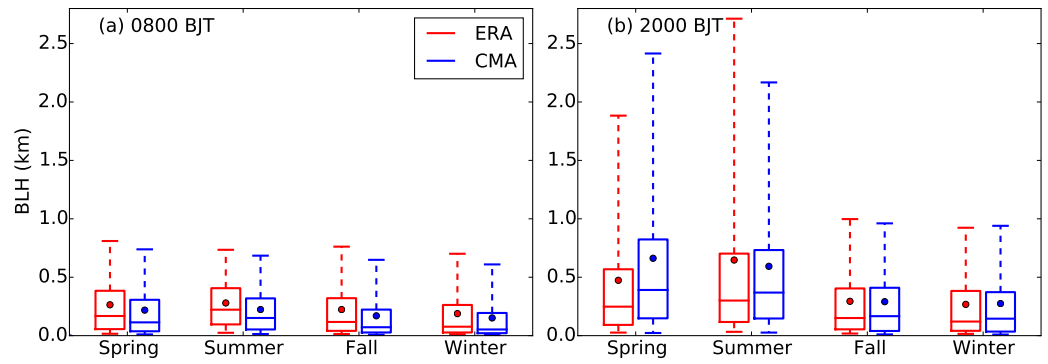

Figure 5. Box-and-whisker plots showing the 5th, 25th, 50th, 75th and 95th percentile values of ERA-BLH (in red) and CMA-BLH (in blue) during each season at (a) 08:00 BJT and (b) 20:00 BJT during the period from January 2011 to July 2015. The dot in each box indicates the mean value of BLHs. Note that there is larger uncertainty for the evening BLH climatologies in (b).
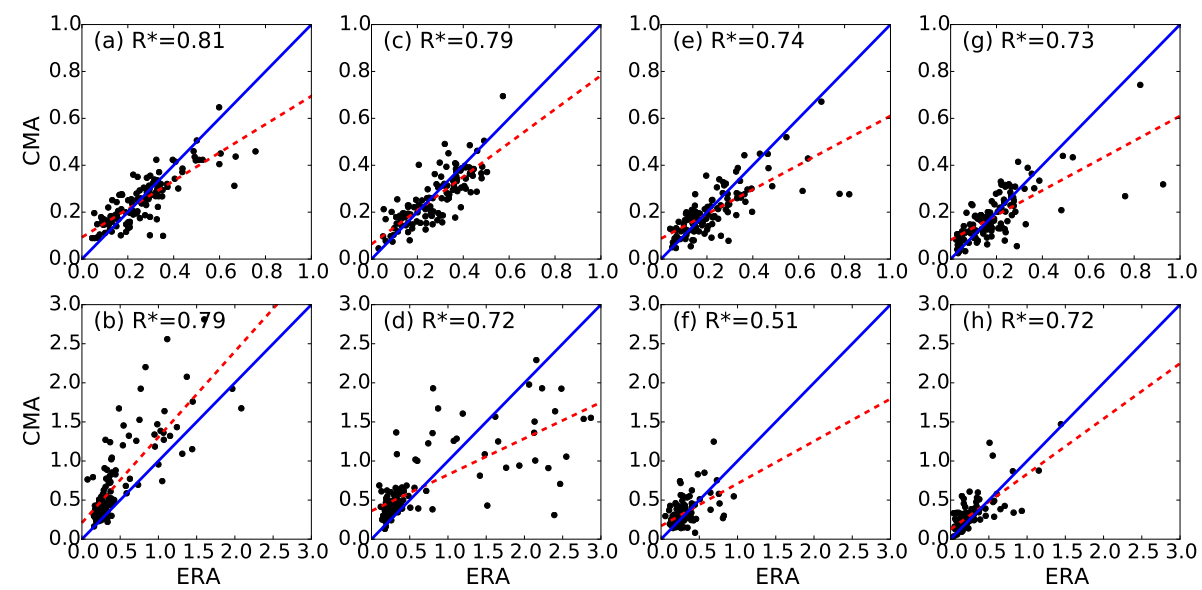

Figure 6. Scatter plots of the seasonally averaged CMA-BLH and ERA-BLH at (top) 08:00 and (bottom) 20:00 BJT in (a, b) spring, $(\mathbf{c}, \mathbf{d})$ summer, $(\mathbf{e}, \mathbf{f})$ fall and $(\mathbf{g}, \mathbf{h})$ winter. The correlation coefficients $(R)$ are given in each panel, where the star superscripts indicate that values are statistically significant $(p<0.05)$.

As illustrated in Fig. 8, both CMA-BLHs and ERA-BLHs at 20:00 BJT demonstrate a strong east-to-west BLH gradient in the warm seasons (spring and summer), with higher BLHs over western China (Fig. 8a-b). The BLH spatial pattern may be caused by the different solar radiation in the west (stronger radiation at an earlier local sidereal time) and east of China at 20:00 BJT.

In fall, it is interesting to note that the east-to-west gradient of BLH is less prominent (Fig. 8c). Likewise, the BLHs during winter in most regions of China are less than $0.3 \mathrm{~km}$, except for the Tibetan Plateau, in which the BLHs can exceed $\sim 0.5 \mathrm{~km}$ at 20:00 BJT.

Since the soundings of $02: 00$ and 14:00 BJT are only launched in summer, the seasonal variation of BLH at these two times cannot be investigated by using the CMA-BLH alone. Therefore, the seasonal variations of BLH at 02:00 and 14:00 BJT are roughly evaluated by using the seasonally averaged ERA-BLHs. It is found that at 14:00 BJT the ERABLHs in spring and summer are higher than those of fall and winter (Fig. 9). At 02:00 BJT, most plain regions of China are covered by a relatively shallow boundary layer, without significant seasonal variation (Fig. 10).

\subsection{Diurnal variation of BLH}

In summer, soundings are available at most of the radiosonde sites four times per day (i.e., 02:00, 08:00, 14:00 and 20:00 BJT), which allows us to investigate the summertime diurnal variation of BLH (Fig. 11a). With the intense solar radiation in summer, the boundary layer is more fully developed during the daytime. At 14:00 BJT, more than half of the seasonally averaged CMA-BLHs are higher than $1 \mathrm{~km}$ (cf., Figs. 9b and 11a). Both the CMA-BLH and ERA-BLH demonstrate a south-to-north gradient of BLH, with higher BLH over the dry northern regions (Fig. 9b), implying that hydrologic factors such as humidity, in addition to solar radiation, may play a role in modulating the spatial distribution of daytime BLH (Seidel et al., 2012).

After sunset, the convective boundary layer undergoes a transition to the nocturnal stable boundary layer. Since the local sidereal time is earlier in the west of China than the east $\left(15^{\circ}\right.$ longitude is equivalent to a $1 \mathrm{~h}$ change in time), the 


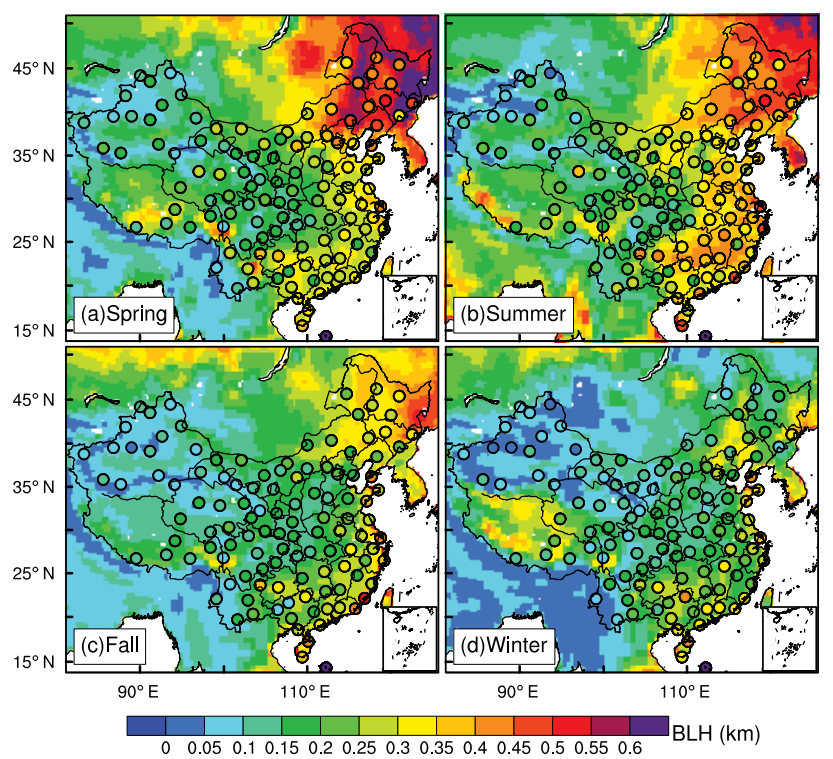

Figure 7. Spatial distributions of the seasonal mean of ERABLH (color shaded) and CMA-BLH (color dots) at 08:00 BJT in (a) spring, (b) summer, (c) fall and (d) winter.

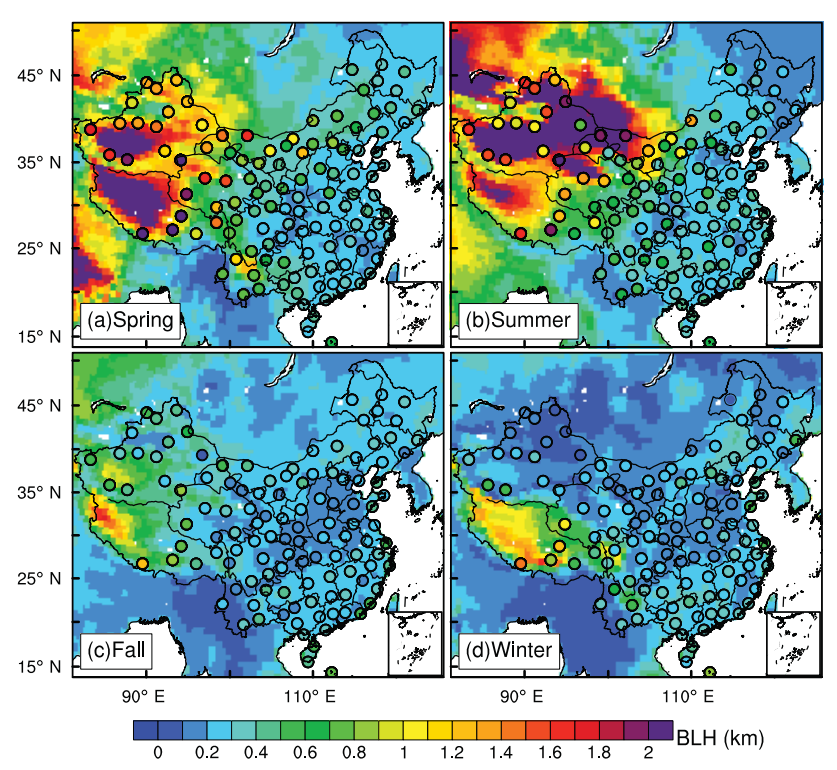

Figure 8. Same as in Fig. 7, but for the spatial distribution of BLHs at 20:00 BJT.

evening transition of boundary layer structure is well manifested by the east-to-west gradient of BLH at 20:00 BJT (Fig. 8b), although the effects of elevation on the spatial distribution of BLH cannot be ignored. During the nighttime, the BLH is less than $0.3 \mathrm{~km}$ over most of China (Figs. 10b and 11a). Comparing the BLH at 02:00 BJT with that of 14:00 BJT, it is found that diurnal amplitude of BLH is stronger in the north and west of China.

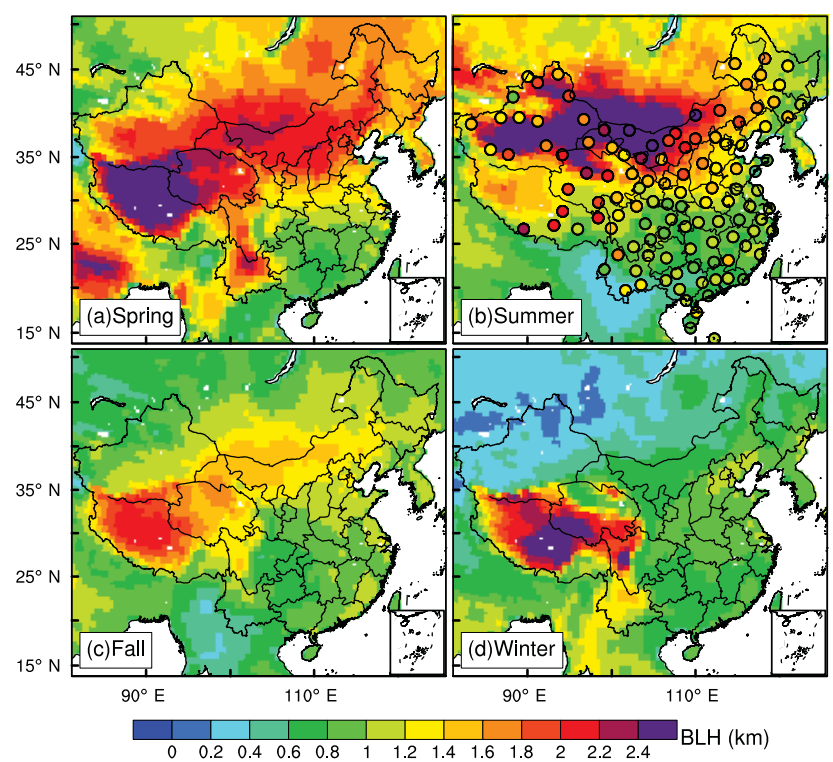

Figure 9. Same as Fig. 7, but for the spatial distribution of BLHs at 14:00 BJT. Note that only the stations that have more than 30 soundings are plotted in (b).

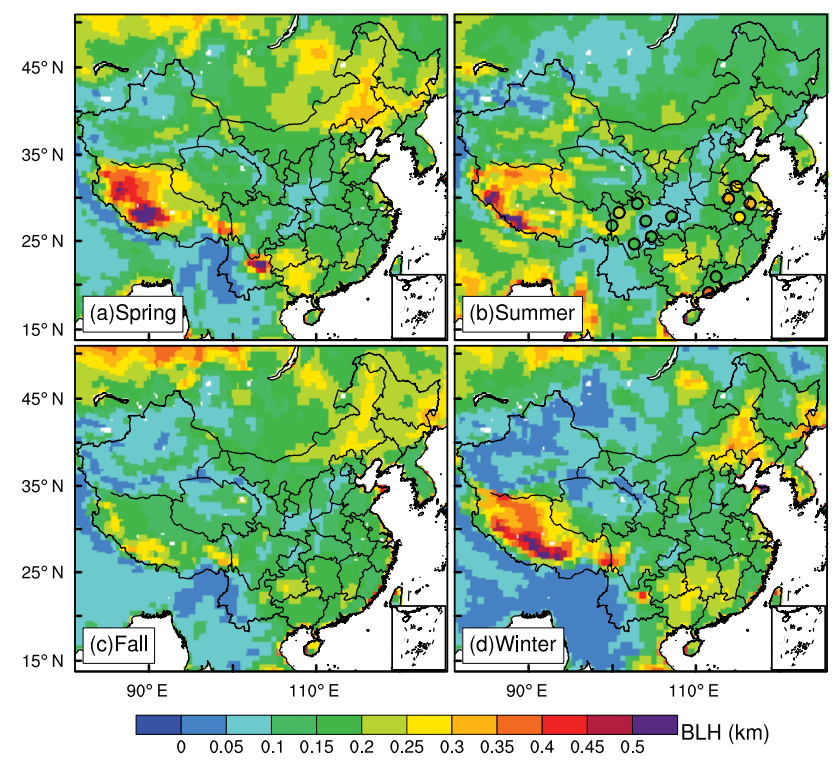

Figure 10. Same as in Fig. 7, but for the spatial distribution of BLHs at 02:00 BJT. Note that only the stations that have more than 30 soundings are plotted in (b).

Similar to the spatial distribution of BLH at 20:00 BJT, the BLH at 08:00 BJT demonstrates the transition from the nocturnal boundary layer to the convective boundary layer (Fig. 7b), characterized by a west-to-east BLH gradient.

With the ground-based cloud cover observations obtained simultaneously at the same sounding sites, the effects of cloud cover on the diurnal evolution of BLH in summer are investigated as well. As illustrated in Fig. 11b, during the 

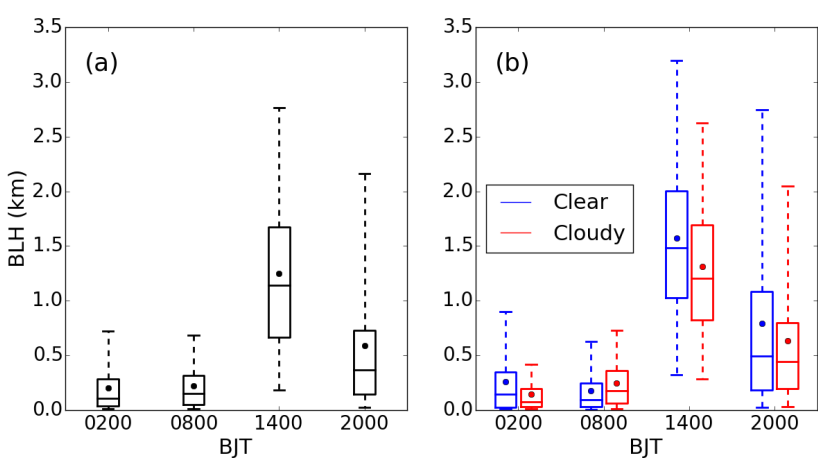

Figure 11. (a) Box-and-whisker plots showing the 5th, 25th, 50th, 75th and 95th percentile values of CMA-BLH at 02:00, 08:00, 14:00 and 20:00 BJT in summer based on all the summertime soundings in China. (b) Box-and-whisker plots showing CMABLH in summer under clear (total cloud cover $\leq 20 \%$, in blue) and cloudy (total cloud cover $\geq 80 \%$, in red) conditions. Note that the rainy days are not considered in (b).

daytime, the development of PBL is typically suppressed due to less solar radiation received at the surface under cloudy conditions. As a result, at 14:00 BJT, the 25th, 50th and 75th percentile values of BLHs decrease by around $0.3 \mathrm{~km}$. The higher mean and 75th percentile values of BLHs under clear conditions could also be observed at 20:00 and 02:00 BJT, which may be related to the larger heat storage of land surface. In contrast, a slightly thicker boundary layer could be formed in the early morning under cloudy conditions.

Using the ERA-BLH as an alternative, the diurnal variations of BLH in the other three seasons are presented in the Supplement (Figs. S5-S7). It is found that the diurnal variation of BLH in spring (Fig. S5) is comparable to that of summer, while the diurnal variation of BLH in fall (Fig. S6) is less prominent. In winter (Fig. S7), due to the weak solar radiation, the development of BLH over the plains of eastern China is severely suppressed, leading to the weakest diurnal variation of BLH during the four seasons over the plains regions.

\subsection{Association of BLHs with related meteorological variables}

As a preliminary effort to explore the potential influence of meteorology on the observed annual cycle of BLH, we turned to ground-based weather observations and soundings that are simultaneously obtained from sites shown in Fig. 1. In particular, the association of CMA-BLH with four other atmospheric variables was evaluated using correlation analyses, including surface pressure, $10 \mathrm{~m}$ wind speed, near-surface temperature and lower tropospheric stability (LTS). The LTS is defined as the difference in potential temperature between $700 \mathrm{hPa}$ and the surface (Slingo, 1987), which can be used to describe the thermodynamical state of the lower troposphere (Guo et al., 2016).

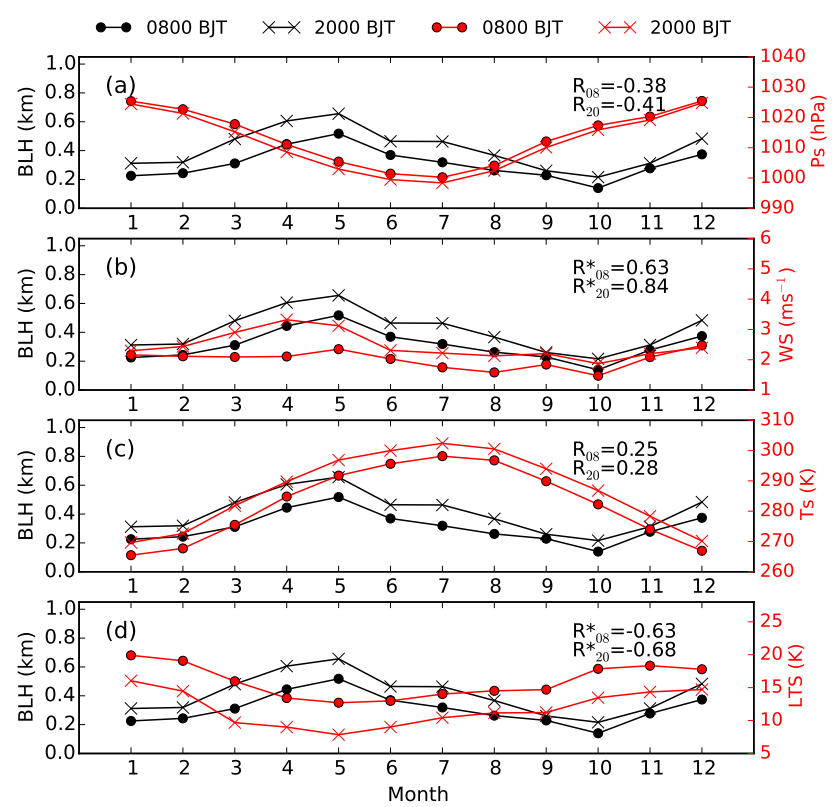

Figure 12. Climatological mean annual cycle of CMA-BLH at the Beijing site $\left(39.8^{\circ} \mathrm{N}, 116.47^{\circ} \mathrm{E}\right)$ at 08:00 BJT (dot symbols) and 20:00 BJT (x symbols), respectively, superimposed by the counterparts of meteorological parameters, including (a) surface pressure $\left(P_{\mathrm{S}}\right)$, (b) $10 \mathrm{~m}$ wind speed (WS), (c) near-surface temperature $\left(T_{\mathrm{S}}\right)$ and (d) lower tropospheric stability (LTS). The correlation coefficients at 08:00 $\left(R_{08}\right)$ and 20:00 BJT $\left(R_{20}\right)$ between CMA-BLH and meteorological parameters are given in each panel as well, and the star superscripts indicate the values that are statistically significant $(p<0.05)$.

For instance, Fig. 12 compares the annual cycles of CMABLH with these four meteorological variables in Beijing. The annual cycles of CMA-BLHs at 08:00 and 20:00 BJT are quite similar. In other words, both CMA-BLHs peak in May, and reach a minimum in October. The annual cycle of CMA-BLH is anti-correlated with the annual cycle of surface pressure (Fig. 12a), implying that the seasonal shift of largescale high-/low-pressure systems can suppress/facilitate the development of the boundary layer through the associated large-scale descending/ascending motion (Liu et al., 2013; Medeiros et al., 2005). The annual cycle of BLH is positively correlated with the annual cycle of near-surface wind speed and temperature (Fig. 12b-c). In addition, the annual cycle of CMA-BLH is anti-correlated with the variation of LTS (Fig. 12d). Compared with the near-surface temperature, the variation of LTS is in closer correspondence with the annual cycle of BLH.

Extending this analysis to the full set of radiosonde stations analyzed, Fig. 13 presents the correlations among these variables at 08:00 and 20:00 BJT. Overall, results obtained at most sites in China as a whole are consistent with those at the Beijing site. In particular, the annual cycle of CMA-BLHs is anti-correlated with the variation of surface pressure and 


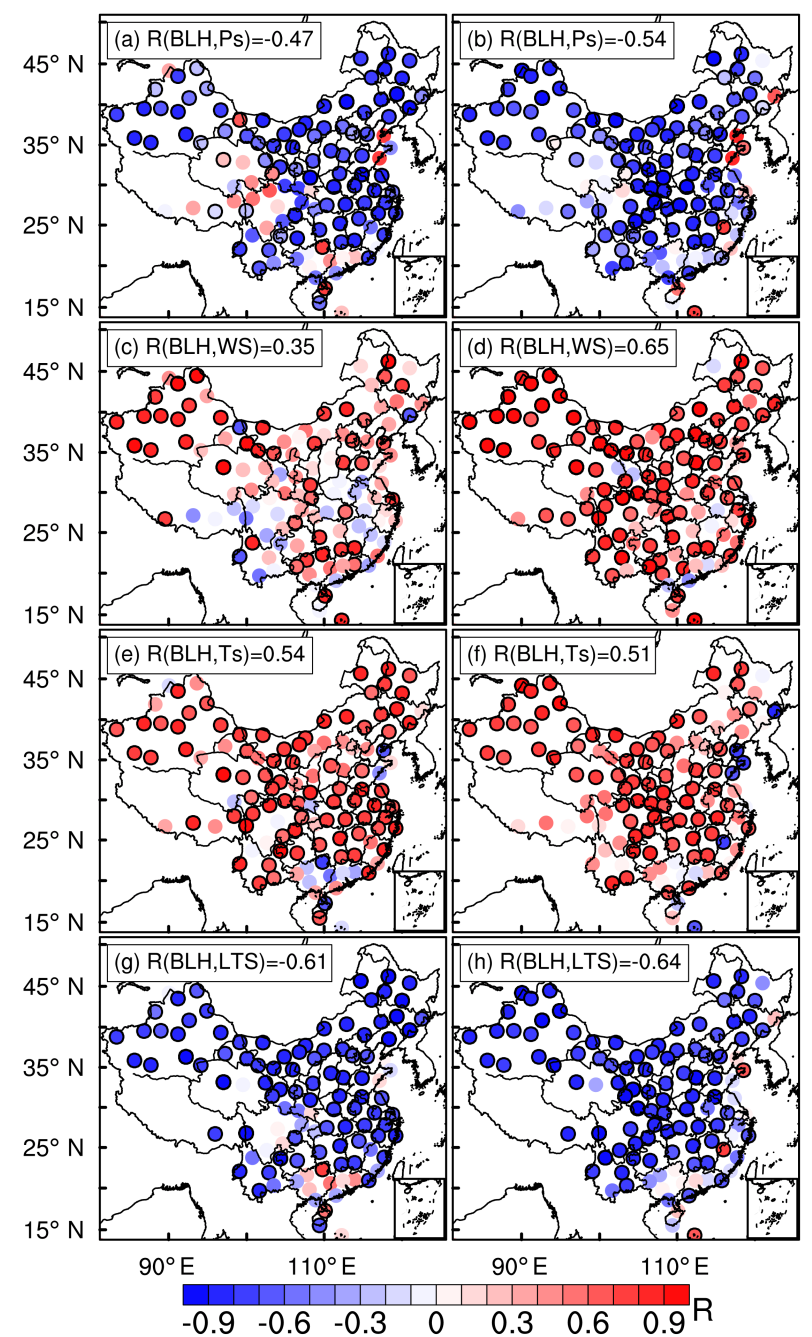

Figure 13. Correlations $(R)$ between mean annual cycles (12monthly values) of CMA-BLH and $(\mathbf{a}, \mathbf{b})$ surface pressure $\left(P_{\mathrm{S}}\right)$, (c, d) $10 \mathrm{~m}$ wind speed, $(\mathbf{e}, \mathbf{f})$ near-surface temperature $\left(T_{\mathrm{S}}\right)$ and (g, h) lower tropospheric stability (LTS), at 08:00 (left panels) and 20:00 BJT (right panels). Symbols outlined in black indicate values that are statistically significant ( $p<0.05$ ), and the overall mean $R$ is given for each panel as well.

LTS (Fig. 13a, b, g, and h), and positively correlated with near-surface wind speed and temperature (Fig. 13c-f). Generally, the correlations are closer at 20:00 BJT, and the correlations are weaker at some sites close to the southern coasts and the east of the Tibetan Plateau, probably due to the modulation of local geographical effects (Stull, 1988). The positive/negative correlations derived from the annual cycle of CMA-BLHs and these four meteorological parameters can also be obtained based on the monthly mean values of CMABLHs and meteorological parameters (Figs. S8-S9).

\section{Concluding remarks}

As the first effort to obtain a sounding-based BLH climatology in China, we have made an extensive use of sounding data from the L-band radiosonde network operated and maintained by CMA from January 2011 to July 2015 . The CMABLHs were also compared with coincident ERA-BLHs using the same bulk Richardson number method.

The mapping of BLH for the first 41 months of the newgeneration radiosonde network provides considerable insight into the large-scale spatiotemporal variations of boundary layer characteristics across China, with continuous radiosonde data studied to date. Previously unknown facts about the boundary layer across whole China were first discovered. A complex pattern of the boundary layer has been revealed, exhibiting strong geographical, diurnal and seasonal variations, corroborated by BLHs derived from ERAInterim. There are substantial influences by elevated terrain features and major land-water boundaries. The association of BLH with solar radiation is a compelling relationship when examining the results for the first 4 years of operation of the radiosonde network.

The sounding observations at 08:00 and 20:00 BJT show that the BLH of spring and summer is generally higher than that of fall and winter. This annual cycle of BLH at most sites is found to be anti-correlated with the annual cycle of surface pressure and LTS, and positively correlated with the near-surface wind speed and temperature. These correlations are stronger at 20:00 BJT.

At 20:00 BJT, the spatial distribution of CMA-BLH exhibits a pronounced east-west gradient of BLH, and a reversed BLH gradient is presented at 08:00 BJT. These spatial patterns of BLH in the early evening and early morning are likely caused by the differing magnitudes of solar radiation in the west (at an earlier local sidereal time) and east of China. The comparison of seasonally averaged CMA-BLH and ERA-BLH at 08:00 and 20:00 BJT shows good agreement. The seasonal and spatial variation of CMA-BLH at these two observation times are generally well reproduced by ERA-Interim reanalysis, although the ERA-Interim reanalysis tends to overestimate the BLH in spring and underestimate the BLH in summer.

The climatological diurnal cycle of BLH, revealed by the soundings four times daily in summer, shows that BLH peaks in the afternoon, and the diurnal amplitude of BLH is higher in the north and west of China. Compared with other seasons, it is found that the diurnal variation of BLH is typically stronger in spring and summer than in fall and winter.

The climatological features of BLH in China revealed here have important implications for better understanding the formation mechanism of aerosol pollution, cloud and even extreme precipitation in China. In the near future, other algorithms for deriving BLH merit a more comprehensive test based on the radiosonde network of China, as well as further 
scrutiny of the sources of uncertainty with regard to the data and methods applied in this study.

\section{Data availability}

The ECMWF reanalysis data are accessible via http://apps. ecmwf.int/datasets/data/interim-full-daily/levtype=sfc/; and the BLH data throughout China retrieved from radiosondes given in this paper are available upon request via email: jpguocams@gmail.com (J. Guo).

\section{The Supplement related to this article is available online at doi:10.5194/acp-16-13309-2016-supplement.}

Acknowledgements. This study is supported by the National Natural Science Foundation of China under grants 91544217 and 41471301, the Ministry of Science and Technology of China under grants 2014BAC16B01 and 2013CB955804, the Guangzhou Science Technology and Innovation Commission under grant 201604020006 and the Chinese Academy of Meteorological Sciences under grant 2014R18. The authors would like to acknowledge CMA for providing the long-term sounding data. Last but not least, we appreciate the constructive comments offered by the three anonymous reviewers tremendously, which greatly improved the quality of this manuscript.

Edited by: R. Zhang

Reviewed by: three anonymous referees

\section{References}

Beyrich, F.: Mixing height estimation from sodar data A critical discussion, Atmos. Environ., 31, 3941-3953, doi:10.1016/S1352-2310(97)00231-8, 1997.

Bian, J., Chen, H., Vömel, H., Duan, Y., Xuan, Y., and Lü, D.: Intercomparison of humidity and temperature sensors: GTS1, Vaisala RS80, and CFH, Adv. Atmos. Sci. 28, 139-146, doi:10.1007/s00376-010-9170-8, 2011.

Chan, K. M. and Wood, R.: The seasonal cycle of planetary boundary layer depth determined using COSMIC radio occultation data, J. Geophys. Res.-Atmos., 118, 12422-12434, doi:10.1002/2013JD020147, 2013.

Dai, C., Wang, Q., Kalogiros, J. A., Lenschow, D. H., Gao, Z., and Zhou, M.: Determining Boundary-Layer Height from Aircraft Measurements, Bound.-Lay. Meteorol., 152, 277-302, doi:10.1007/s10546-014-9929-z, 2014.

Dee, D. P., Uppala, S. M., Simmons, A. J., Berrisford, P., Poli, P., Kobayashi, S., Andrae, U., Balmaseda, M. A., Balsamo, G., Bauer, P., Bechtold, P., Beljaars, A. C. M., van de Berg, L., Bidlot, J., Bormann, N., Delsol, C., Dragani, R., Fuentes, M., Geer, A. J., Haimberger, L., Healy, S. B., Hersbach, H., Hólm, E. V., Isaksen, L., Kållberg, P., Köhler, M., Matricardi, M., McNally, A. P., Monge-Sanz, B. M., Morcrette, J.-J., Park, B.-K., Peubey,
C., de Rosnay, P., Tavolato, C., Thépaut, J.-N., and Vitart, F.: The ERA-Interim reanalysis: configuration and performance of the data assimilation system, Q. J. Roy. Meteor. Soc., 137, 553-597, doi:10.1002/qj.828, 2011.

Ding, A. J., Huang, X., Nie, W., Sun, J. N., Kerminen, V.-M., Petäjä, T., Su, H., Cheng, Y. F., Yang, X.-Q., Wang, M. H., Chi, X. G., Wang, J. P., Virkkula, A., Guo, W. D., Yuan, J., Wang, S. Y., Zhang, R. J., Wu, Y. F., Song, Y., Zhu, T., Zilitinkevich, S., Kulmala, M., and Fu, C. B.: Black carbon enhances haze pollution in megacities in China, Geophys. Res. Lett., 43, 1-7, doi:10.1002/2016GL067745, 2016.

Eresmaa, N., Karppinen, A., Joffre, S. M., Räsänen, J., and Talvitie, H.: Mixing height determination by ceilometer, Atmos. Chem. Phys., 6, 1485-1493, doi:10.5194/acp-6-1485-2006, 2006.

Garratt, J.: Review: the atmospheric boundary layer, Earth-Sci. Rev., 37, 89-134, doi:10.1016/0012-8252(94)90026-4, 1994.

Guo, $\mathrm{H} ., \mathrm{Xu}, \mathrm{M}$. , and $\mathrm{Hu}, \mathrm{Q} .:$ Changes in near-surface wind speed in China: 1969-2005, Int. J. Climatol., 31, 349-358, doi:10.1002/joc.2091, 2011.

Guo, J.-P., Zhang, X.-Y., Che, H.-Z., Gong, S.-L., An, X., Cao, C.-X., Guang, J., Zhang, H., Wang, Y.-Q., and Zhang, X.C.: Correlation between PM concentrations and aerosol optical depth in eastern China, Atmos. Environ., 43, 5876-5886, doi:10.1016/j.atmosenv.2009.08.026, 2009.

Guo, J. P., Zhang, X. Y., Cao, C. X., Che, H. Z., Liu, H. L., Gupta, P., Zhang, H., Xu, M., and Li, X. W.: Monitoring haze episodes over Yellow Sea by combining multisensor measurements, Int. J. Remot. Sens., 31, 4743-4755, doi:10.1080/01431161.2010.485213, 2010.

Guo, J. P., Deng, M. J., Lee, S.-S., Wang, F., Li, Z., Zhai, P. M., Liu, H., Lv, W. T., Yao, W., and Li, X.: Delaying precipitation and lightning by air pollution over Pearl River Delta. Part I: observational analyses, J. Geophys. Res.-Atmos., 121, 6472-6488, doi:10.1002/2015JD023257, 2016.

Guo, S., Hu, M., Zamora, M. L., Peng, J., Shang, D., Zheng, J., Du, Z., Wu, Z., Shao, M., and Zeng, L.: Elucidating severe urban haze formation in China, P. Natl. Acad. Sci. USA, 111, 17373-17378, 2014.

Hennemuth, B. and Lammert, A.: Determination of the atmospheric boundary layer height from radiosonde and lidar backscatter, Bound.-Lay. Meteorol., 120, 181-200, doi:10.1007/s10546-0059035-3, 2006.

Holzworth, G. C.: Estimates of mean maximum mixing depths in the contiguous United States, Mon. Weather Rev., 92, 235-242, doi:10.1175/1520-0493(1964)092<0235:EOMMMD>2.3.CO;2, 1964.

Hu, X. M., Nielsen-Gammon, J. W., and Zhang, F.: Evaluation of three planetary boundary layer schemes in the WRF model, J. Appl. Meteorol. Clim., 49, 1831-1844, doi:10.1175/2010JAMC2432.1, 2010.

Hu, X., Ma, Z., Lin, W., Zhang, H., Hu, J., Wang, Y., Xu, X., Fuentes, J. D. and Xue, M.: Impact of the Loess Plateau on the atmospheric boundary layer structure and air quality in the North China Plain?: A case study, Sci. Total Environ., 499, 228-237, doi:10.1016/j.scitotenv.2014.08.053, 2014.

Lee, X., Gao, Z., Zhang, C., Chen, F., Hu, Y., Jiang, W., Liu, S., Lu, L., Sun, J., Wang, J., Zeng, Z., Zhang, Q., Zhao, M., and Zhou, M.: Priorities for Boundary-Layer Meteorology Re- 
search in China, B. Am. Meteorol. Soc., 96, ES149-ES151, doi:10.1175/BAMS-D-14-00278.1, 2015.

Liu, J., Huang, J., Chen, B., Zhou, T., Yan, H., Jin, H., Huang, Z., and Zhang, B.: Comparisons of PBL heights derived from CALIPSO and ECMWF reanalysis data over China, J. Quant. Spectrosc. Ra., 153, 102-112, doi:10.1016/j.jqsrt.2014.10.011, 2015.

Liu, S. and Liang, X.-Z.: Observed Diurnal Cycle Climatology of Planetary Boundary Layer Height, J. Climate, 23, 5790-5809, doi:10.1175/2010JCLI3552.1, 2010.

Liu, X. G., Li, J., Qu, Y., Han, T., Hou, L., Gu, J., Chen, C., Yang, Y., Liu, X., Yang, T., Zhang, Y., Tian, H., and Hu, M.: Formation and evolution mechanism of regional haze: a case study in the megacity Beijing, China, Atmos. Chem. Phys., 13, 4501-4514, doi:10.5194/acp-13-4501-2013, 2013.

Medeiros, B., Hall, A., and Stevens, B.: What Controls the Mean Depth of the PBL?, J. Climate, 18, 3157-3172, doi:10.1175/JCLI3417.1, 2005.

Miao, S., Dou, J., Chen, F., Li, J., and Li, A.: Analysis of observations on the urban surface energy balance in Beijing, Sci. China Earth Sci., 55, 1881-1890, doi:10.1007/s11430-012-44116, 2012.

Miao, Y., Hu, X.-M., Liu, S., Qian, T., Xue, M., Zheng, Y., and Wang, S.: Seasonal variation of local atmospheric circulations and boundary layer structure in the Beijing-Tianjin-Hebei region and implications for air quality, J. Adv. Model. Earth Syst., 7, 1-25, doi:10.1002/2015MS000522, 2015.

Miao, Y., Liu, S., Zheng, Y., and Wang, S.: Modeling the feedback between aerosol and boundary layer processes: a case study in Beijing, China, Environ. Sci. Pollut. Res., 23, 3342-3357, doi:10.1007/s11356-015-5562-8, 2016.

Norton, C. L. and Hoidale, G. B.: The Diurnal Variation of Mixing Height by Season over White Sands Missile Range, New Mexico, Mon. Weather Rev., 104, 1317-1320, doi:10.1175/15200493(1976)104<1317:TDVOMH>2.0.CO;2, 1976.

Peng, J., Hu, M., Guo, S., Du, Z., Zheng, J., Shang, D., Zamora, M. L., Zeng, L., Shao, M., and Wu, Y.-S.: Markedly enhanced absorption and direct radiative forcing of black carbon under polluted urban environments, P. Natl. Acad. Sci. USA, 113, 42664271, 2016.

Quan, J., Gao, Y., Zhang, Q., Tie, X., Cao, J., Han, S., Meng, J., Chen, P., and Zhao, D.: Evolution of planetary boundary layer under different weather conditions, and its impact on aerosol concentrations, Particuology, 11, 34-40, doi:10.1016/j.partic.2012.04.005, 2013.

Sawyer, V. and Li, Z.: Detection, variations and intercomparison of the planetary boundary layer depth from radiosonde, lidar and infrared spectrometer, Atmos. Environ., 79, 518-528, 2013.

Seibert, P.: Review and intercomparison of operational methods for the determination of the mixing height, Atmos. Environ., 34, 1001-1027, doi:10.1016/S1352-2310(99)00349-0, 2000.

Seidel, D. J., Ao, C. O., and Li, K.: Estimating climatological planetary boundary layer heights from radiosonde observations: Comparison of methods and uncertainty analysis, J. Geophys. Res., 115, D16113, doi:10.1029/2009JD013680, 2010.

Seidel, D. J., Zhang, Y., Beljaars, A., Golaz, J.-C., Jacobson, A. R., and Medeiros, B.: Climatology of the planetary boundary layer over the continental United States and Europe, J. Geophys. Res.Atmos., 117, D17106, doi:10.1029/2012JD018143, 2012.
Slingo, J.: The development and verification of a cloud prediction scheme for the ECMWF model, Q. J. Roy. Meteor. Soc., 113, 899-927, 1987.

Stull, R. B. (Ed.): An Introduction to Boundary Layer Meteorology, Springer Netherlands, Dordrecht, 1988.

Tang, G., Zhang, J., Zhu, X., Song, T., Münkel, C., Hu, B., Schäfer, K., Liu, Z., Zhang, J., Wang, L., Xin, J., Suppan, P., and Wang, Y.: Mixing layer height and its implications for air pollution over Beijing, China, Atmos. Chem. Phys., 16, 2459-2475, doi:10.5194/acp-16-2459-2016, 2016.

Vogelezang, D. H. P. and Holtslag, A. A. M.: Evaluation and model impacts of alternative boundary-layer height formulations, Bound.-Lay. Meteorol., 81, 245-269, doi:10.1007/BF02430331, 1996.

Wang, Y., Khalizov, A., Levy, M., and Zhang, R.: New Directions: Light absorbing aerosols and their atmospheric impacts, Atmos. Environ., 81, 713-715, doi:10.1016/j.atmosenv.2013.09.034, 2013.

Wood, R.: Stratocumulus Clouds, Mon. Weather Rev., 140, 2373 2423, doi:10.1175/MWR-D-11-00121.1, 2012.

Xie, B., Fung, J. C. H., Chan, A., and Lau, A.: Evaluation of nonlocal and local planetary boundary layer schemes in the WRF model, J. Geophys. Res.-Atmos., 117, 1-26, doi:10.1029/2011JD017080, 2012.

Zhang, H., Wang, Y., Hu, J., Ying, Q., and Hu, X.-M.: Relationships between meteorological parameters and criteria air pollutants in three megacities in China, Environ. Res., 140, 242-254, doi:10.1016/j.envres.2015.04.004, 2015.

Zhang, R., Khalizov, A. F., Pagels, J., Zhang, D., Xue, H., and McMurry, P. H.: Variability in morphology, hygroscopicity, and optical properties of soot aerosols during atmospheric processing, P. Natl. Acad. Sci. USA, 105, 10291-10296, doi:10.1073/pnas.0804860105, 2008.

Zhang, R., Wang, G., Guo, S., Zamora, M. L., Ying, Q., Lin, Y., Wang, W., Hu, M., and Wang, Y.: Formation of Urban Fine Particulate Matter, Chem. Rev., 115, 3803-3855, doi:10.1021/acs.chemrev.5b00067, 2015.

Zhang, W., Guo, J., Miao, Y., Liu, H., Zhang, Y., Li, Z., and Zhai, P.: Planetary boundary layer height from CALIOP compared to radiosonde over China, Atmos. Chem. Phys., 16, 9951-9963, doi:10.5194/acp-16-9951-2016, 2016.

Zhang, Y., Zhang, S., Huang, C., Huang, K., Gong, Y., and Gan, Q.: Diurnal variations of the planetary boundary layer height estimated from intensive radiosonde observations over Yichang, China, Sci. China Ser. E, 57, 2172-2176, doi:10.1007/s11431014-5639-5, 2014.

Zhao, X., Zhang, X., Xu, X., Xu, J., Meng, W., and Pu, W.: Seasonal and diurnal variation of ambient $\mathrm{PM}_{2.5}$ concentration in urban and rural environments in Beijing, Atmos. Environ., 43, 28932900, doi:10.1016/j.atmosenv.2009.03.009, 2009. 